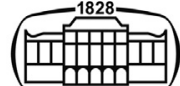

AKADÉMIAI KIADÓ

\title{
Modernization imposed: SOM's practice in China - A case study of Wuhan
}

\author{
Kangwei $\mathrm{Tu}^{1,2 *} \odot$ and Andras Reith ${ }^{3}$
}

\section{Pollack Periodica \\ An International Journal \\ for Engineering and Information Sciences}

16 (2021) 2, 163-169

DOI:

$10.1556 / 606.2020 .00249$

(c) 2020 The Author(s)

\author{
${ }^{1}$ Marcel Breuer Doctoral School, Faculty of Engineering and Information Technology, University of \\ Pécs, Boszorkány u. 2, H-7624 Pécs, Hungary \\ ${ }^{2}$ Faculty of Civil Engineering, Architecture and Environment, Hubei University of Technology, \\ Wuhan, China \\ ${ }^{3}$ Advanced Building and Urban Design, Hungary and Faculty of Engineering and Information \\ Technology, University of Pécs, Boszorkány u. 2, H-7624 Pécs, Hungary
}

Received: May 29, 2020 • Revised manuscript received: October 16, 2020 • Accepted: November 15, 2020 Published online: March 23, 2021

\section{ORIGINAL RESEARCH PAPER}

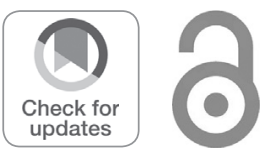

* Corresponding author. E-mail: tu.kangwei@qq.com

\section{KEYWORDS}

overseas design, modernization, grid road system

\section{INTRODUCTION}

The modernization process of Wuhan can be seen as the epitome of the modernization of thousands of Chinese cities. With a history of more than two thousand years, it was once one of the 'four famous towns' and 'the most prosperous place in central Chu'. Before the founding of the People's Republic of China, it still maintained a relatively primitive, traditional city image with Chinese classical imprint. In the 1950', Wuhan's urban construction sought a breakthrough, and mainly based on the urban plan of Soviet experts, trying to unify the three towns of Wuhan with the European-style urban axis and square system, forming an integrated urban spatial structure system [1]. With the great impact of reform and opening up, the traditional urban pattern of small streets and alleys can no longer meet the needs of urban development - Wuhan, like many other Chinese cities, started the pace of major demolition and reconstruction in the late 1990s and embarked on the road of 'modernization'. In this way, these cities have been hard to find any material basis as a famous historical and cultural city in the surging tide of economic development.

As China becoming a leading economic power of the world, modernization is one of the fundamental tools [2]. Modernization is now happening in China, and of course it did happen in the west. Before China adopted the concept of 'modernization', it had actually used 'westernization' for nearly a century. After the decline of Europe after World War II, it began to use 'Americanization'. Therefore, with the reform and opening up, the emergence of overseas design forces, from architectural landmarks to core urban design in major Chinese cities, the participation of foreign design firms is indispensable. All these questions of urban transformation and urban renewal that Chinese cities are generally facing not only 
provideing great opportunities for foreign design companies to enter the Chinese market, but also need the experience of the western society and the answers from the United States.

\section{SOM IN CHINA}

\subsection{The product of multidisciplinary collaboration}

Of all these foreign design forces, Skidmore, Owings and Merrill (SOM) have undoubtedly become one of the best 'localized' companies in China-in recent years, as an American firm. It has frequently won the opportunities of architectural design and urban design in the key areas of China's core cities. SOM has designed more than 300 projects in 40 Chinese cities to date and continues to gain market share in this country. According to data from SOM, China has become the second largest market (see Fig. 1). So, how did it beat so many strong competitors?

In addition to those eye-catching achievements, the multidisciplinary collaboration that SOM has always adopted, especially the cooperative working mechanism with local planners, planning research institutes, government departments and developers, which has won more and more Chinese customers' favor. For example, the projects of Beijing financial street, Shanghai Chuangzhi world and Wuhan Hanzheng street reconstruction were all completed by SOM in cooperation with local design institutes. This kind of strategic cooperation between overseas design institutions and local design institutions is now common in China. The reason is that although overseas design institutions have advanced design concepts, strong technical strength and design experience in large-scale projects, different cultural backgrounds, differences in design concepts and ways of thinking, language barriers, misunderstanding of norms and other factors are likely to lead to the unsmooth progress of projects. Therefore, the strategic cooperation between local design institutions and overseas design institutions achieves the goal of integrating the advantageous resources of both sides and achieving mutual benefit and win-win. Just behind the scenes, SOM exported 'American methods and procedures for problem solving, management and construction',

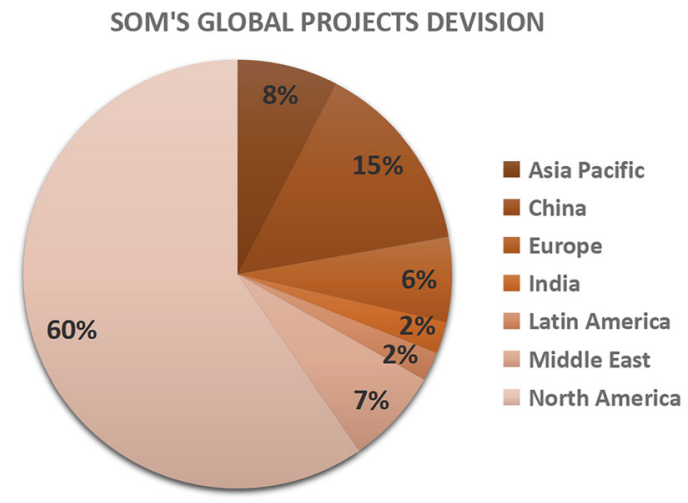

Fig. 1. Photograph showing SOM's global projects division (Source: on the basis of SOM data plotted by author) which greatly changed the urban landscape of 'modern' China.

\subsection{Nine planning principles for the twenty-first century}

According to John Lund Kriken, SOM's former president's book [3], SOM's urban design works generally focus on nine characteristics: sustainability, accessibility, diversity, open space, compatibility, incentive policy, adaptability, the identification and intensity of development. SOM's works in China basically reflect the above characteristics, especially the open space and the intensity of development.

Open space: according to the nine principles, for every 10 ha of land, at least 1 ha of large urban landscape should be arranged, and community parks must be within a 3-5 minute walk of the residents. Therefore, different from other large-scale urban public projects, landscape area is extremely concentrated and huge in SOM's plan.

The intensity of development: it is closely related to the public transport system, and the more overlap with public transport, the higher intensity of development, the more complexity of function. SOM advocates building compact cities, as opposed to sprawling cities, with strict limits on the size of plots in order to leave enough land for ecology and agriculture. This move coincides with what the Chinese government now calls a 'Small Neighborhood, Dense Network'.

Therefore, under the dual effect of open space and the intensity of development, SOM's unique urban space experience is actually created between 'loose and tight'. However, SOM's urban design strategy was carried out so thoroughly that the urban design projects in China were highly consistent (see Fig. 2). But the identification of the nine principles was rare, as Shenzhen Planning and Land Bureau once pointed out in the feedback of SOM's Futian Urban Design Plan that the plan should avoid becoming another European or American city blocks, standing on the height of the world and the times [4]. So it is not difficult to imagine, those who live in these newly-built blocks will have quite similar experiences, while urban life and its quality had always prominent position throughout history [5].

\section{SOM'S PRACTICE IN WUHAN}

SOM started to dabble in Wuhan market around 2008. And the reconstruction plan of Hanzheng Street completed in 2013 is a project integrating the main features of SOM's design. It is a case of SOM's style.

\subsection{The best street in the world}

Hanzheng Street, located on the north bank where the two rivers meet, is the geographical center of the three towns in Wuhan. As the earliest central street in the history of Hankou, the crisscrossed old alleys are the well-deserved heart of the city and the root of commerce. Rising in the late Ming dynasty after the diversion of the Han River, it was 

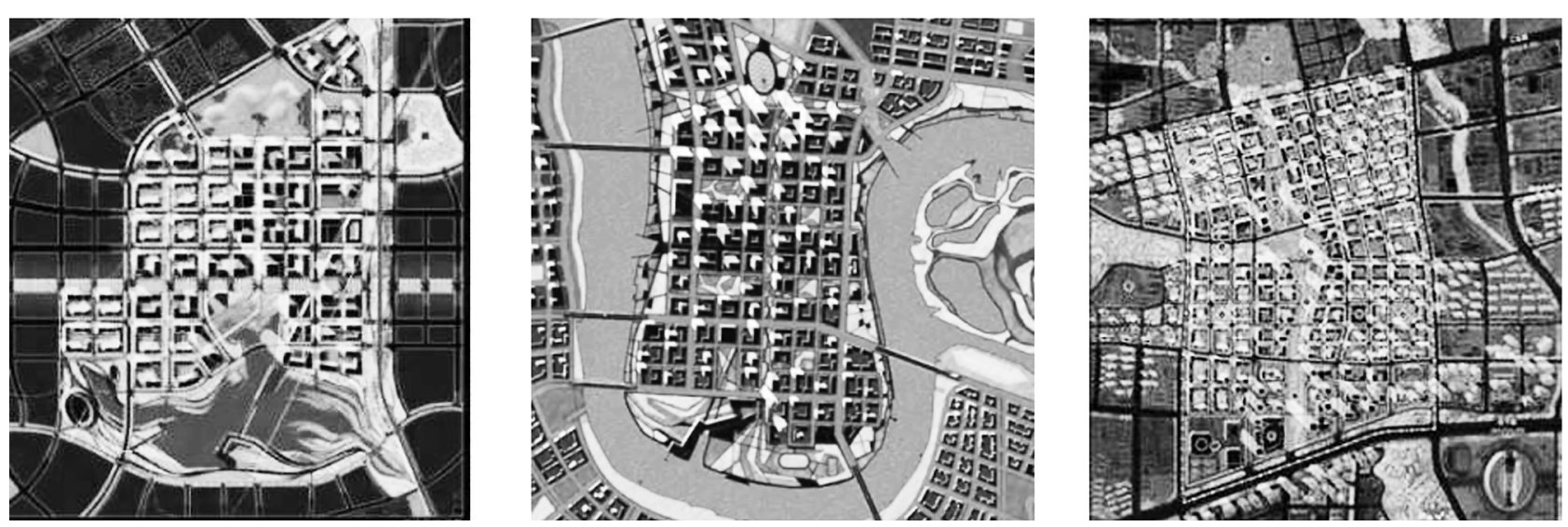

Fig. 2. SOM's projects in Wuhan, Jinan and Beijing of China (Source: Author's plot)

once the center of international trade, whose transactions were all over the country, even Europe, America, East Asia and South Asia, known as 'the Best Street in the World'. During the period of the Republic of China, the economic center of Hankou was transferred from Hanzheng Street to Jianghan road, and the Hanzheng Street took a back seat to small commodity market. After the founding of new China, big industry was forcibly embedded, and the individual economy of Hanzheng Street was suppressed. In the 1980s, with the business philosophy of 'Small Street, Big Market', 'small commodity, big circulation', it resumed its decadeslong tradition of free trade and opened up as a small commodity market once again. After 1990s, with the shrinking of waterways and the impact of modern business model, Hanzheng Street lost its geographical position, and the vibrant 'Street + Residence' space mode shaped in the era of agricultural economy could no longer meet the necessary function by the result of modern trading volume expands. 'The Best Street in the World' gradually declined [6].

\subsection{Reconstruction dilemma}

Early since the $1990^{\mathrm{s}}$, Wuhan government has started to explore the transformation pattern of Hanzheng Street. However, due to the limited land, dense buildings, poor traffic, as well as the large number of demolition and reconstruction areas and long interest chains, the reconstruction is very difficult and has no obvious effect. As a result, the reconstruction period of Hanzheng Street has been prolonged time and again, and it has been called the largest and most difficult reconstruction project in the city. In 2011, a big fire of Hanzheng Street made Wuhan government make a painful decision and announced to move the whole market of Hanzheng Street to the north of Hankou.

Before SOM took over the reconstruction plan of Hanzheng Street, a lot of local agencies like Wuhan urban planning and design institute had made several rounds of plans, but they were never approved by the government. Therefore, Wuhan urban planning and design institute and Hellmuth Obtat Kassabaum (HOK) formed a joint design team to complete the conceptual planning of Hanzheng
Street and compile the land use planning of Wuhan Hanzheng Street area. But when the project was ready to be implemented, the implementability of the plan became the focus of a new round of disputes, and the plan got stranded. So, in 2012, Wuhan government re-invited well-known domestic and foreign institutions to jointly conduct research and planning with the goal of 'implementation'.

It has solid basis for making 'implementability' as a core requirement of the plan. The difficulty of the previous HOK scheme is reflected in the fact that its grand idea of 'sky street' not only lacks convincing theoretical basis, but also appears to be impossible under the financing difficulty with 'zero foundation'.

\subsection{SOM plan: the process of the transformation and implementation of design concept}

3.3.1. Functional orientation and scale prediction. According to the study by Cushman \& Wakefield, the function is positioned as 'Central Service Area of Hanzheng Street'. With double Trading \& Tourism (TT) as the core, double drive and double support the development of the region will be promoted. It is expected that in the next 10-20 years, Hanzheng Street will be built into a world-class business, finance and tourism center.

The total coverage of the central service area of Hanzheng Street is 3.46 square kilometers, and the total amount of construction is estimated to be about 12 million square meters, an increase of $57 \%$ compared with the current situation (7.652 million square meters), with a gross plot ratio of 4.0. By 2030, the resident population is expected to reach 158,000 with 300,000 jobs.

3.3.2. Development of design concept. SOM's idea conform to the central axis of 'Zhongshan Park - South Bank Mouth - Hongshan Square' proposed in the overall master plans of Wuhan, and puts forward 'People-shaped' axis scheme (see Fig. 3). It is divided into two directions near Hanzheng street: one leads east to Dragon King Temple, connecting the financial island of sky street part in the future, and connecting Wuchang through the Yangtze 


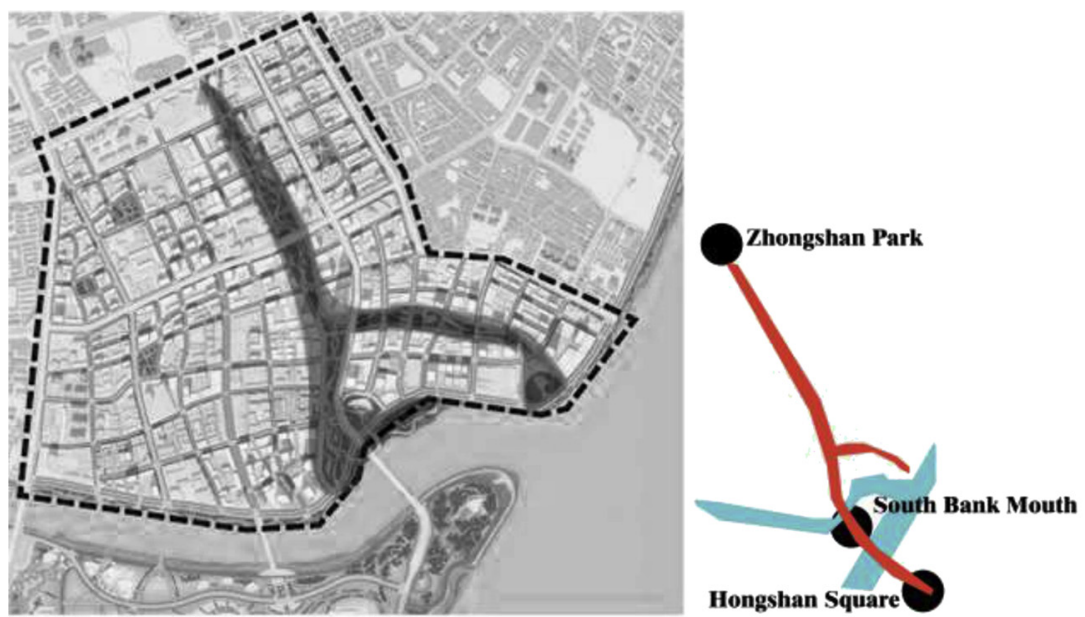

Fig. 3. 'People-shaped' axis of the plan (Source: Author's plot)

river. Another leads south to the financial island and the east piece of Hanzheng Street, through the Han River connecting Hanyang.

This plan not only continues the central axis of the city, but also connects important nodes of the three towns of Wuhan with the Hanzheng Street as a link, and defines the 'Urban Island' where the two rivers meet. Finally, it forms a spatial structure of one Axis ('Human-shaped' axis), one Belt (Zhongshan Avenue Commercial Belt) and Four Districts (Financial Core Area, Heritage Area, Commercial Complex Area and Northern Living Area).

After dealing with the relationship between Hanzheng Street and the city, SOM first reorganize the road network within the area. Optimize the layout, plan to form a new pattern of 'Small Neighborhood, Dense Network'. By increasing fast access, the number of arterial roads and optimizing road functions, the road network density will be increased to $15.57 \mathrm{~km} / \mathrm{km}^{2}$, which is 2.3 times of the current $6.6 \mathrm{~km} / \mathrm{km}^{2}$, basically formed an evenly and regularly divided block pattern.

In addition, a north-south rail line (line 13) is planned to be added to the central axis of Hankou, and an increasing Lshaped metro line is planned to connect to line 2, line 13 , line 6 and line 1, so as to improve the coverage density of public transportation in the region and make up for the weakness of north-south traffic links. In the area where the public transport stations are concentrated, three landmark buildings are arranged along the 'People-shaped' green axis to build the overall image of financial core area in the riverside. In addition to the existing buildings of the heritage areas, other areas will be constructed in accordance with the newly defined block system to form the main commercial and living districts.

3.3.3. The design strategy of 'Americanization'. Through a general analysis of SOM Hanzheng Street Plan, it is not difficult to find that its core strategy relies on absolute control of the blocks with traffic planning as a guide.

Urban design in the United States has gone through three main stages. The first stage advocated the idea of
'Building a city that is not too ugly'. The second stage reconstructed and supplemented the situation of the first stage, and the third stage put special emphasis on blocks scale and development density. So SOM's design strategy reflects the latest features of the third stage of US Urban design.

Just like the downtown area of New York and Chicago, the dimensions of the blocks are evenly distributed, and the length and width of a standard block is maintained around 80-120 m. For example, Seattle $70, \cdot 75 \mathrm{~m}^{2}$, Chicago $95, \cdot 120$ $\mathrm{m}^{2}$, Indianapolis $125, \cdot 125 \mathrm{~m}^{2}$, and the spatial pattern of blocks in the center areas of these big cities is basically intact, unchanged during 100-200 years, showing good adaptability and stability (see Fig. 4).

This kind of homogeneous, regularly, highly orderly 'ideal blocks' is widely used by American cities for its integral, large-scale change of urban appearance in a short time, and it has been very mature in the commercial development of downtown areas of the United States [7]. Therefore, it has been copied to Chinese cities almost as it is, and the specific operation flow is like this - any area regardless of its history, regardless of its place, all can be divided by $80-120 \times 80-120 \mathrm{~m}$ grids, and this is the first step. Second, by building a circle of skirts tightly along the building line, the boundary of every unit is strengthened. In the third step, high-rise buildings are dotted at each unit's corner. And the space left in the middle will be of public or green function at last (see Fig. 5). Above all is the standardized answer of 'Modernization' that SOM teaches to Chinese cities. It indeed brings huge economic benefit just as it did in US. Taking the East Section of Hanzheng Street as an example, the whole area is divided into eight plots, A1, A2, A3, B1, B2, C1, C2 and C3. The size of each plot is very close, with the smallest plot of 1.06 ha and the largest plot of 1.93 ha. In 2017, Fuxing group [8] won lots a1-3, b1-2 and c2-3 at a price of 13.01 billion yuan. Same story happened to Yinfeng plot as well, it was acquired by Shanghai Fuyu Investment Co., Ltd. at a price of 4.27 billion yuan, with a unit price of 53.49 million yuan, becoming the 'Land King' of Wuhan land market in 2014. 

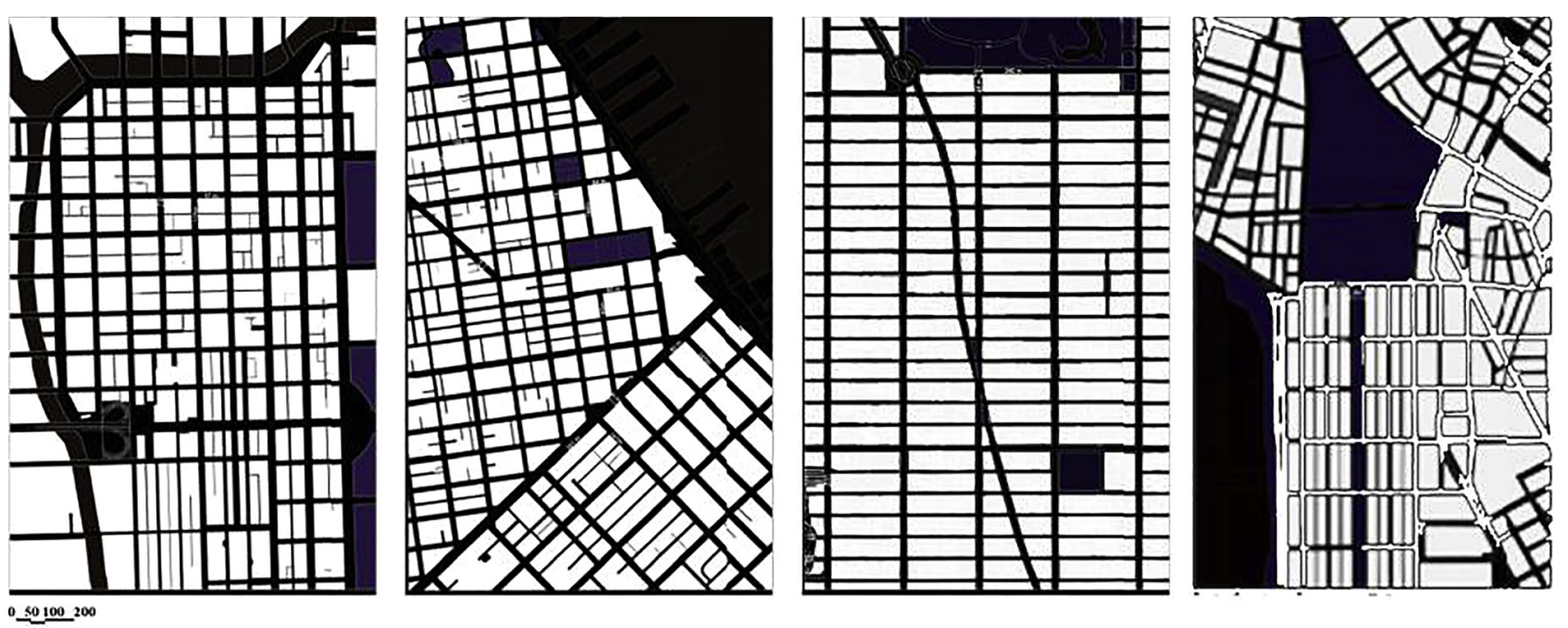

Fig. 4. The pattern of blocks in downtown areas of Chicago, San Francisco, New York and Boston (Source: Author's plot)
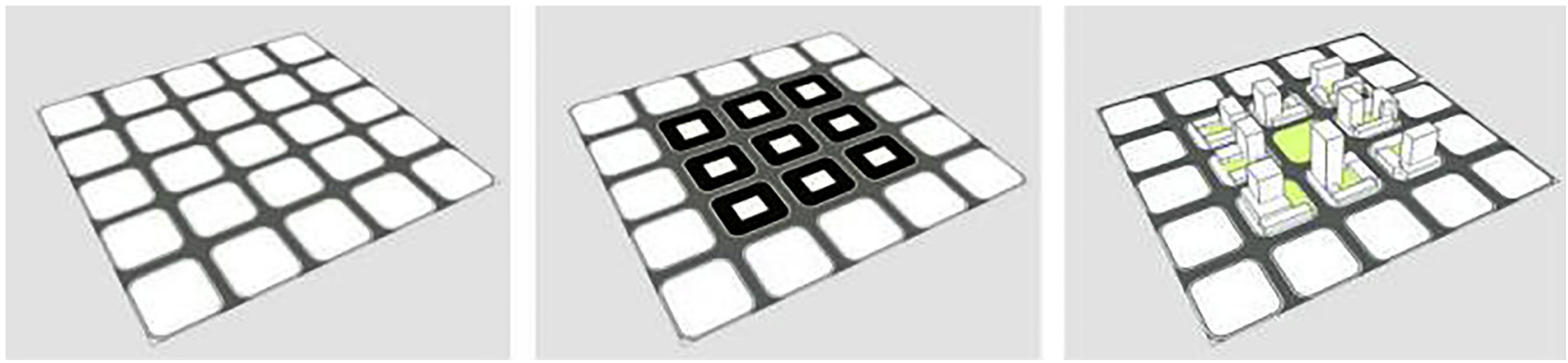

Fig. 5. Strategy of 'Small Neighborhood, Dense Network' in the SOM's projects (Source: Author's plot)

3.3.4. The cost of 'American' modernization. While the city gains huge economic benefits, the unique 'Fish-bone' space that has been developed and matured since the Ming and Qing dynasties are now almost eliminated.

This kind of 'Fish-bone' Street+Lane system developed in a short period of time as a water transport wharf and commercial outlet, that was, the 'street' in East-West direction was parallel to Han River, and the 'lane' in NorthSouth direction was vertical to the Han River. 'Water' and 'lanes' were like lips and teeth, which depended on each other [9]. These dense parallel lanes along the main ridge of Hanzheng Street which like a fish-bone were the blood vessels and ties of the region. The lane was generally 130$250 \mathrm{~m}$ in length, and the intervals - the width of each 'Fishbone' was 15-20 m, which was exactly the width of the main street occupied by two households back to back. This was the 'module' of Hanzheng Street, which originated from the logic of commerce and life in the old time and had been continued for more than 100 years.
Now the continuation of this ancient module is interrupted by the modern 'Grids'. Is there, as Le Corbusier put as module gives us the satisfaction of order through obtaining the ability of measure and unify [10]. However, this may not be the fact. As the cells of urban space, the texture unit of any area is a growth process. Its rich spatial relationship is the historical memory of a city's daily life. Through data and texture comparison of Hanzheng street before and after, it is obvious to tell that the thousand-yearold traditional urban spatial pattern has been suddenly interrupted in one night (see Table 1 and Fig. 6).

Three most obvious aspects of the changes will be specifically analyzed, discovering the logic and purpose behind:

- The shape of blocks changed from elongated to more regular squares. With the increase of the scale of modern buildings, the strip land obviously greatly restricts the layout of buildings, while when the size of the street area is controlled at $80-120 \mathrm{~m}$ square block; it brings great

Table 1. The comparison of data before and after Hanzheng Street

\begin{tabular}{|c|c|c|c|c|c|c|c|}
\hline & Block Length & Block Width & Plot Area & Setbacks & $\mathrm{H} / \mathrm{D}$ & $\mathrm{W} / \mathrm{D}$ & Continuity \\
\hline Before & $130-250 \mathrm{~m}$ & $15-20 \mathrm{~m}$ & $2000-5000 \mathrm{~m}^{2}$ & $1-2 \mathrm{~m}$ & $1-2$ & $0.2-0.3$ & $95-100 \%$ \\
\hline After & $80-120 \mathrm{~m}$ & $80-120 \mathrm{~m}$ & $10000-20000 \mathrm{~m}^{2}$ & $4-5 \mathrm{~m}$ & $>2$ & $1-2$ & $80-90 \%$ \\
\hline
\end{tabular}



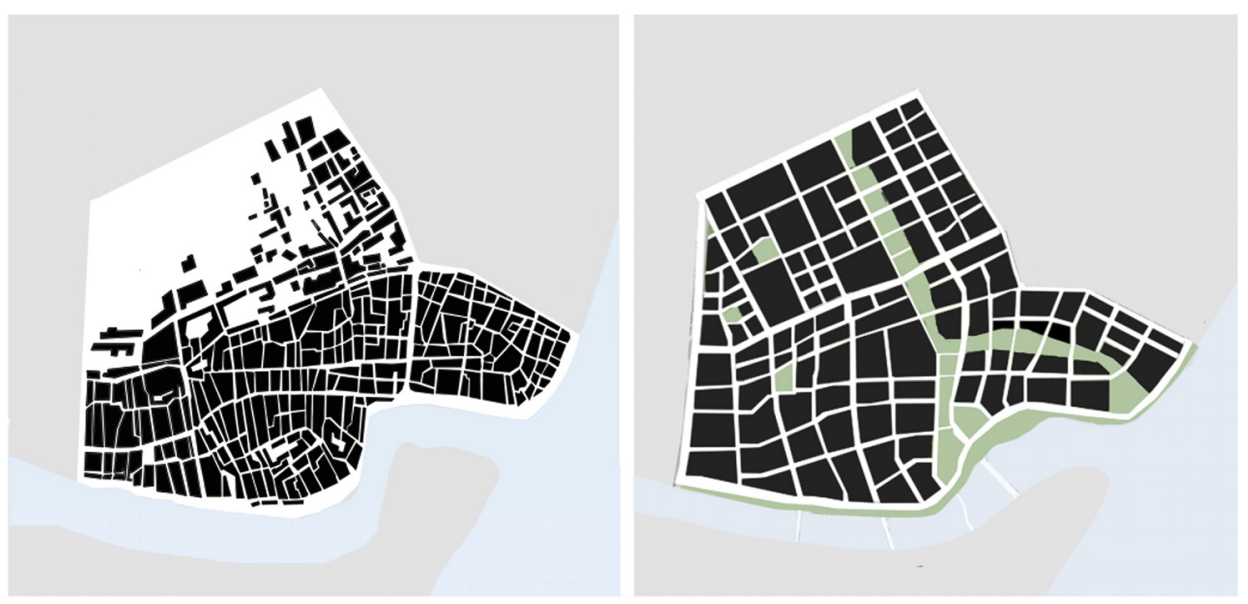

Fig. 6. The comparison of texture before and after in Hanzheng Street (Source: Author's plot)

flexibility and enough space. As an integer multiple of the common column grid spacing, $80-120 \mathrm{~m}$ is also more conducive to the smooth connection and execution of the whole process from urban design to architectural design, providing the very modular basis for the construction of high-rise buildings. The experience of using grid system in American history also directly reflects that it can be built on largest scale repeatedly at lowest cost, and can change the urban appearance to the greatest extent in the shortest time, thus becoming a necessary tool for urban development;

- The direction of the road is from the direction parallel to the Han River to the indifference guide. The main streets before were parallel to the Han River from east to west, while the lanes were perpendicular to them, extending the street life to the waterside, thus confirming the affinity and attachment to the nature and water in the spatial structure. As a result, the value of the plot decreases as the distance from The Han River increases. After the reconstruction, the road network has nearly equal space spacing, and the four-way structure makes it have no obvious preferences in either direction, not highlighting any advantages of waterfront plots. Its balanced distribution reduces the economic range between each plot and thus enlarges the total value of the whole area;

- Public space from riverside to hinterland. In Chinese society, the boundary between public and private is blurred. The public space is mostly overlapped with the private one, and it is arranged by the side of the house or by the road or by the river in a small scale. The transformed scheme increases the centralized large-scale green land in the central part of the region, which seems to sacrifice the construction land, but actually artificially enhances the landscape advantage in the central part of the region, especially around the green belt, thus raising total land price.

The important changes of the above three are all directly driven by economic reasons and become the carrier and internal logic for urban modernization's giving priority to economic efficiency. Chinese cities copy the standard of
"American modernization" and blindly pursue economic interests at the expense of long history, romantic tradition and local characteristics of Chinese cities. In its place is the same stereotype just as any international metropolitan that is again- 'Grid road system + High-rise buildings'.

\section{CONCLUSION}

SOM exported American methods and procedures of solving problems, managing and building cities, which greatly changed the urban appearance of China. The violent promotion of 'Grid road system + High-rise buildings' mode caused huge cultural conflicts and historical rupture, and the ancient urban fabric is embedded with distorted images of the new city.

'Modernization' in the United States is almost equivalent to 'Capitalization', but modernization should not simply edit social relations according to the logic of capitalism, leading to the infiltration of capitalist relations into daily life and daily space, making all social relations dependent on economic relations. Now the government clearly realizes that the urban design is now playing more and more important role in urban development control, and can be used as a means of revitalizing the urban economy. So it is easy to take the 'Modernization' of US and 'Modernization' of China homogeneity, hoping to obtain rapid growth of economy in a short period of time.

However, this kind of homogeneity helps Chinese cities gaining short-term benefits while suffering long-term damage, as city is an overlapping, fuzzy, multi-interwoven whole. Mixed functions, small-scale urban blocks have been replaced by a grid of modern blocks driven by the logic of centralization. The gentle and rational way of 'urban renewal' was replaced by the crude and brutal 'urban governance'. The reconstruction of 'Big demolition and Big construction' completely cut off the historical context and spontaneous order of the city. The original ecological and local communities were lost, and the city's historical memory and sense of place were erased. 
Now, Chinese cities have been filled with American city blocks or international versions already. In today's complex and changing world, China should face up to the cultural value of Chinese cities while learning advanced overseas design concepts, instead of following the results of rights and ideal planning and ignoring the fact of natural generation and systematic evolution. It is time to seek flexible and diverse ways to build 'Modern' cities with Chinese characteristics, while respecting differences and historical context.

\section{ACKNOWLEDGMENTS}

The Authors heartily thank the advice from Charlie Q. L. Xue and appreciate kindly help from Sophie Suo, Feifei Ren and the encouragement from Vaneeta D. Andrea.

\section{REFERENCES}

[1] Y. Long, Informal City (in Chinese). Nanjing: Southeast University Press, 2010.
[2] J. Gyergyák, "Thoughts from the dynamical changing city, Shanghai," Pollack Period., vol. 11, no. 1, pp. 129-143, 2016.

[3] J. L. Kriken and P. E. R. Rapaport, City Building: Nine Planning Principles for the 21st Century. Princeton Architectural Press, 2010.

[4] Urban Planning and Architecture Design of Shenzhen Central District 1996-2002 (in Chinese). Shenzhen Planning and Resource Bureau, China Architecture \& Building Press, 2002.

[5] É. Kovacs, "City success index, urban development, a possible method to research urban strategy," Pollack Period., vol. 11, no. 3, pp. 27-42, 2016.

[6] G. Wang, "The syntax of streets: Historic inspection of Hanzheng Street in Wuhan," PhD Thesis, Huazhong University of Science and Technology, 2008.

[7] M. Biddulph. The Evolution of American Urban Design: A Chronological Anthology. Academy Press, 2002.

[8] S. Zhao, Hanzheng Street's Big MAC plot will enter the market with a high profile (in Chinese). [Online]. Available: https:// wuhan.news.fang.com/2016-11-16/23520515.html. Accessed: Nov. 26, 2016.

[9] Historical Atlas of Wuhan. Wuhan Historical Atlas Compilation Committee, (Mandarin Chinese). Beijing: China Map Publisher, 1998.

[10] L. Corbusier, Vers une Architecture. Editions Flammarion, 2008. 